(Figure 1). Lipids were started at $2 \mathrm{~g} /(\mathrm{kg} . \mathrm{d})$ and increased to $3 \mathrm{~g} /$ (kg.d) the following day.

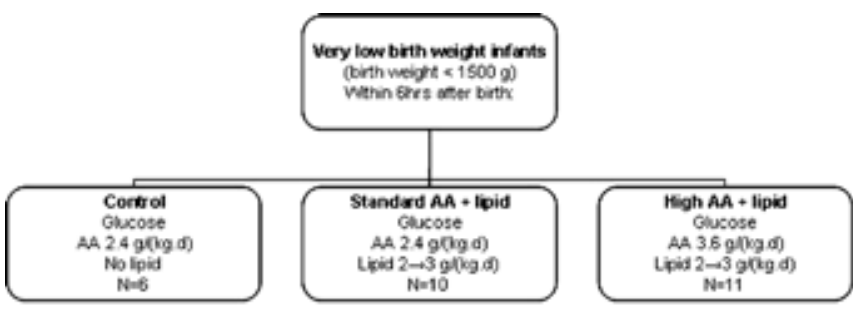

Abstract 356 Figure 1 Study design

At postnatal day 2, infants received a primed continuous infusion of $\left[{ }^{13} \mathrm{C}_{6},{ }^{15} \mathrm{~N}\right]$ leucine. Mass spectrometry was used to determine the fractional and absolute albumin synthesis rates (FSR and ASR, respectively).

Results Albumin FSR, concentration, and ASR were not significantly different between groups (Figure 2; median, IOR).
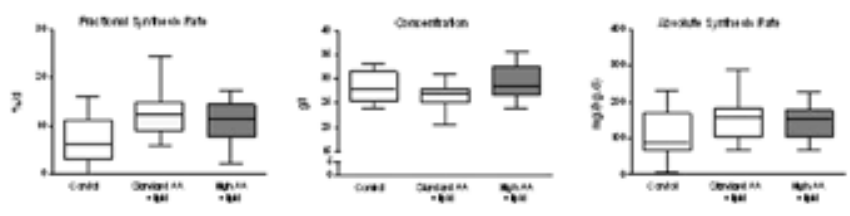

Abstract 356 Figure 2 Albumin FSR, concentration, and ASR

Conclusion Albumin concentration was in normal range in all groups. Albumin synthesis rates and concentration are not increased upon introduction of $2 \mathrm{~g}$ lipids/(kg.d) and 3.6g AA/ $(\mathrm{kg} . \mathrm{d})$ from birth onwards.

\section{HUMAN MILK BILE SALT-STIMULATED LIPASE: THE DYNAMIC CHANGES DURING LACTATION}

doi:10.1136/archdischild-2012-302724.0357

'P Piemontese, ${ }^{2} \mathrm{P}$ Roncada, ${ }^{3} \mathrm{~A}$ Soggiu, ${ }^{3} \mathrm{~L}$ Bonizzi, ${ }^{4} \mathrm{~A}$ Budelli, ${ }^{5} \mathrm{C}$ Agostoni, ${ }^{\mathrm{M}} \mathrm{ML}$ Giannì, IP Roggero, 'F Mosca. 'Department of Maternal and Pediatric Sciences, NICU Fondazione IRCCS 'Ca' Granda' Ospedale Maggiore Policlinico, University of Milan; ${ }^{2}$ Istituto Sperimentale Italiano Lazzaro Spallanzani; ${ }^{3}$ DIPAV, University of Milan; ${ }^{4} \mathrm{Heinz}$ Italia Spa; ${ }^{5}$ nstitute of Pediatrics, University of Milan, Fondazione IRCCS 'Ca' Granda' Ospedale Maggiore Policlinico Milan, Milan, Italy

Background and Aims The efficient digestion of milk triglycerides is guaranteed by the combined action of gastric lipase, colipasedependent pancreatic lipase, and bile salt-stimulated lipase (BSSL). Human milk contains the major part of BSSL. Data regarding the dynamic changes of human milk BSSL are scarce.

The aim of this study was to evaluate the changes of human milk BSSL content at different stages of lactation by proteomic techniques.

Methods We designed a prospective longitudinal study. Human milk samples were collected from 18 healthy mothers who delivered a singleton term newborn (Gestational age 37-41 weeks) on the $3^{\text {th }}$, $7^{\text {th }}, 15^{\text {th }}$, and $60^{\text {th }}$ postpartum day. Proteomic techniques were carried out to evaluate different profile expression of BSSL in milk: in particular SDS-PAGE analysis coupled with LC-MS MS mass spectrometry.

Results BSSL levels increased significantly from the $3^{\text {th }}$ to the $60^{\text {th }}$ postpartum day (figure).

\section{human milk BSSL}

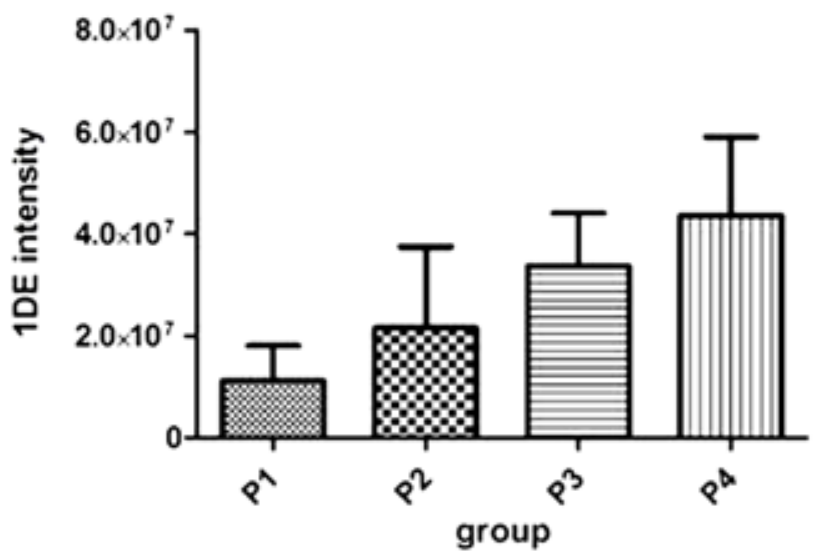

Abstract 357 Figure 1 Human milk BSSL at different study points

Conclusions The increased levels of human milk BSSL could compensate for low endogenous capacity to digest dietary fat in early life as efficient absorption of lipids is important, not only for energy utilization but also for optimal growth and functional neurodevelopment.

\section{THE EFFECT OF GALACTAGOGUE HERBAL TEA ON OXIDANT AND ANTI-OXIDANT STATUS OF HUMAN MILK}

doi:10.1136/archdischild-2012-302724.0358

S Kavurt, AY Bas, 0 Aydemir, H Yücel, N Demirel. Neonatology, Etlik Zübeyde Hanım Women's Health Teaching and Research Hospital, Ankara, Turkey

Background and Aims Human milk (HM) has a number of antioxidant constituents which may protect newborns against oxidative damage. Poor HM production is the most frequent cause of breastfeeding failure. Galactagogues are believed to stimulate initiation and maintenance of HM production. Herbal tea containing fenugreek has recently been presented in the market. We aimed to compare global oxidant and antioxidant capacity of HM among mothers drinking galactagogue herbal tea or not.

Methods Volunteer mothers 18-35 years of age without any antenatal or perinatal risk factors. Milk samples were collected in the first day after delivery. Mothers were randomly assigned to receive galactagogue herbal tea (Humana still-tee $\left.{ }^{\circledR}\right) 3$ cups/day or same amount of water as placebo. Second samples were obtained 7-10 days later. The total antioxidant capacity (TAC), total oxidant status (TOS) and the oxidative stress index (OSI) were compared between groups.

Results Subjects were randomly assigned to herbal tea $(n=40)$ and placebo $(n=40)$ groups. In first and second samples TAC, TOS and OSI were similar in both groups. TAC ( $p=0.375$ and $p=0.058)$ was lower and TOS ( $p=0.382$ and $p=0.118)$ was higher in second samples compared to first samples in both groups but not significantly. In second samples OSI ( $p=0.024$ and $p=0.007)$ increased significantly compared to first day in each group.

Conclusions Galactagogue herbal tea used in this study has no effect on global oxidant and antioxidant status of HM. Oxidative stress index increases in course of lactation compared to colostrum.

\section{INTRASUBJECT VARIATION IN ESTIMATES OF NEONATAL INTRAHEPATOCELLULAR LIPID USING 1H NMR SPECTROSCOPY}

